
АНАЛИЗ ВРАЧЕБНЫХ ОШИБОК В МЕДИЦИНСКОЙ ПРАКТИКЕ

\author{
Е. Х. Баринов ${ }^{1}$, Д. В. Сундуков ${ }^{2}$ \\ ${ }^{1}$ Московский государственный медико-стоматологический университет; \\ Кафедра судебной медицины и медицинского права, \\ ${ }^{2}$ Российский университет дружбы народов, кафедра судебной медицины, Москва
}

\title{
Analysis of Doctors' Errors in Medical Practice
}

\author{
E. Kh. Barinov ${ }^{1}$, D. V. Sundukov \\ ${ }^{1}$ Department of Forensic Medicine and Medical Law, Moscow State University of Medicine and Dentistry, Moscow, Russian Federation \\ ${ }^{2}$ Department of Forensic Medicine, People's Friendship University of Russia, Moscow, Russian Federation
}

В статье приводятся сведения об изучении нежелательных исходов в медицинской практике, приводятся сведения из экспертной практики. Ключевые слова: нежелательный исход, ятрогения, судебно-медицинская экспертиза.

The paper presents information on the studies of poor outcomes in medical practice and that from expert practice. Key words: poor outcome, iatrogenia, forensic medical examination.

Анализ и изучение данных о нежелательных исходах в медицине приобрели несколько необходимых здравоохранению сфер применения. Одна из них - это объективизация данных путем измерения различных параметров каждого случая ненадлежащей медицинской помощи для установления степени риска определенных вмешательств, вероятности неудач у врачей разных специальностей. Второй аспект - принятие управленческих решений на основе полученной информации для совершенствования систем компенсации ущерба пациентам. Важна эта информация и для прогнозирования того, какие виды юридической ответственности будут превалировать в медицине в ближайшие годы.

Актуальность данной проблемы обусловлена необходимостью расширения знаний в этой области в течение последних лет и отражает мировую тенденцию, а также потребность в изучении данных о «медицинских происшествиях». Недостаток информации по этой теме сочетается с противоречиями в понятийно-терминологическом аппарате [1-3].

Новизна изучения обусловлена существованием проблемы в новых социально-экономических условиях, при обновлении нормативной, организационной и технологической базы здравоохранения. Имеются принципиальные пути решения этой проблемы современными методами, и существует отрасль (судебно-медицинская экспертиза), в которой может быть получен основной объем однородной информации [3].

Исследование неблагоприятных исходов медицинской помощи как предмета судебно-медицинской экспертизы позволило выделить неблагоприятные исходы с признаками ятрогении и без признаков ятрогении. Признаки ятрогении включают - наличие вреда здоровью, возникновение вреда при исполнении профессиональных или служебных обязанностей медицинским персоналом, причиненный вред находится в прямой связи с действиями ввиду нарушения медицинских стандартов и нормативных актов. К признакам ятрогении не относятся - отсутствие вреда здоровью и/или отсутствие связи вреда здоровью с оказанием медицинской помощи [1].

Юридически значимой для наступления ответственности является только прямая связь, а юридически безразличной считается косвенная (случайная) связь. Для дифференциров-

Адрес для корреспонденции (Correspondence to):

Баринов Евгений Христофорович

E- mail: EV.BARINOV@mail.ru ки прямой и косвенной связи практическое значение имеют следующие критерии:

- объективные факторы ненадлежащего оказания медицинской помощи и неблагоприятного исхода;

- субъективные препятствия оказания медицинской помощи со стороны больного;

- степень соблюдения общепринятых медицинских правил и рекомендаций;

- степень соблюдения соответствующих нормативных актов; сопоставление результатов оказания медицинской помощи в различных лечебно-профилактических учреждениях.

Нарушения, допущенные медицинскими работниками при оказании медицинской помощи, можно систематизировать по четырем ятрогенным сферам: тактико-диагностической; лечебной; информационно-деонтологической; организационной.

Изучение медицинских характеристик субъективной стороны ненадлежащего оказания медицинской помощи имеет значение для систематизации экспертной оценки качества медицинской помощи. Этот материал может использоваться с целью установления вероятности определенных факторов риска для врачей разных специальностей и для больных, имеющих особенности заболевания. Аналогично могут быть установлены специальности с минимальным риском неблагоприятного исхода [3].

При экспертной оценке выявлено преобладание следующих видов ненадлежащей медицинской помощи: неправильное - на этапе профилактики и реабилитации; несвоевременное - при диагностике; неправильное и недостаточное - в процессе лечения.

Исследование объективных факторов, влияющих на неблагоприятный исход, позволило выделить наиболее значимые: редкость заболевания, атипичность течения болезни, естественный патоморфоз, сочетание или конкуренция нозологических форм, тяжелое состояние больного, кратковременность пребывания в лечебно-профилактическом учреждении, отсутствие условий оказания помощи в лечебно-профилактическом учреждении, тяжесть заболевания, аллергические реакции, избыточный вес, хронические инфекции.

Для объективной и всесторонней оценки обстоятельств медицинского происшествия существенное значение должна иметь связь между допускаемыми дефектами медицинской помощи и особенностями поведения больных. Следует отметить наиболее характерные изменения особенностей поведения больного, именуемых субъективными препятствиями со стороны больного для ненадлежащего оказания медицинской по- 
мощи: часто встречающиеся - аггравация и симуляция, поиск «лучшего» врача, грубая неосторожность пациента, асоциальное поведение; редко встречающиеся - требования вмешательства без показаний, нарушение режима, самолечение, нарушение правил пользования медицинской услугой.

В последние годы были проведены исследования нежелательных исходов в практике ортопедической, хирургической, терапевтической стоматологии, абдоминальной хирургии, пластической хирургии и косметологии, акушерстве-гинекологии и неонатологии [4]. Целенаправленного исследования выявления нежелательных исходов в анестезиологии-реаниматологии не проводилось.

В период времени с 2000 по 2011 гг. в Бюро судебно-медицинской экспертизы ДЗ Москвы было проведено 1025 судебно-медицинских экспертиз по гражданским делам, из них 508 экспертиз было связано с врачебными делами.

Проведенный анализ показывает, что наименьшее количество исков предъявляется к специалистам в области анестезиологии-реаниматологии. При этом в большинстве случаях, связанных с дефектами оказания медицинской помощи при проведении анестезии, вина ложится на специалистов хирургического профиля.

Примером этому может служить следующий случай.

При проведении амбулаторных операций в 442 окружном военном клиническом госпитале ЛенВО двум военнослужащим, у одного из которых имелся подмозольный абсцесс в области 2-го пальца левой кисти, а у второго - паронихий 1 пальца правой кисти, военным хирургом, выполнявшим

\section{Литература}

1. Баринов E. X., Сундуков Д. В. «Медицинские» дела в гражданском процессе: роль судебно-медицинской экспертизы. Общая реаниматология 2011; VII (4): 67-69.

2. Баринов Е. Х., Сундуков Д. В. Судебно-медицинская экспертиза по гражданским делам - состояние, проблемы, перспективы. Общая реаниматология 2011; VII (5): 75-80.

3. Баринов E. X., Тихомиров А. В. Судебно-медицинская экспертиза при решении вопросов, связанных с «медицинскими» спорами. Медицинская экспертиза и право 2010; 6: 5-7.

4. Паиинян Г. А., Ромодановский П. О., Баринов Е. Х., Черкалина Е. Н К проблеме проведения комиссионных судебно-медицинских экспертиз по материалам уголовных и гражданских дел, связанных с оказанием медицинской помощи в акушерстве и неонатологии. Медищинское право 2009; 3: 44-46. обязанности помощника дежурного хирурга, и дежурной медсестрой по приемному отделению, при проведении указанным военнослужащим местной анестезии был введен бензин вместо новокаина, что привело в конечном итоге к инвалидизации обоих пациентов. В процессе судебно-медицинской экспертизы были проанализированы условия, способствовавшие этому происшествию, дана оценка предпринятых медицинскими работниками мер с целью предотвращения тяжелых последствий для пациентов и приведен перечень необходимых в тех условиях действий.

Примером же дефектов оказания медицинской помощи в практике анестезиологии может служить следующее наблюдение:

Гр-н И., 31 года, проходил лечение в Томской городской больнице по поводу черепно-мозговой травмы, где была произведена операция - декомпрессивная костно-пластическая трепанация черепа слева. Через 4 месяца была назначена плановая операция - краниопластика с целью закрытия костного дефекта в левой теменно-височной области. Проводившийся врачом-анестезиологом Ш. наркоз с неудачной 3-х кратной попыткой интубации трахеи привел к развитию у пациента глубокой необратимой гипоксии с расстройством дыхания и сердечно-сосудистой деятельности, закончившейся смертью на операционном столе.

Все вышеизложенное свидетельствует о необходимости продолжения детального исследования нежелательных исходов в практике анестезиологии-реаниматологии.

\section{References}

1. Barinov E. Kh., Sundukov D. V. Medical matters in a civil procedure: role of forensic medical examination. Obshchaya Reanimatologiya «(In Rus.)» 2011; VII (4): 67-69.

2. Barinov E. Kh., Sundukov D. V. Forensic medical examination in civil cases: status, problems, perspectives. Obshchaya Reanimatologiya «(In Rus.)» 2011; VII (5): 75-80.

3. Barinov E. Kh., Tikhomirov A. V. The forensic medical examination at the decision of questions, connected with the «medical» disputes. Meditsinskaya ekspertiza I pravo «(In Rus.)» 2010; 6: 5-7.

4. Pashinyan G. A., Pomodanovskii P. O., Barinov E. Kh., Cherkalina E. N. To the problem of forensic medical examinations commission on the materials of the criminal and civil cases relating to the provision of medical care in obstetrics and neonatology. Meditsinskoe pravo «(In Rus.)» 2009; 3: 44-46.

Поступила 14.12.11

\section{CARDIAC CALENDAR 2012}

$34^{\text {th }}$ Annual Meeting \& Workshops Society

of Cardiovascular Anesthesiologists. Boston, $M A$.

April 28 - May 2, 2012. www.scahq.org

on Intensive Care and Emergency Medicine. Brussels, Belgium.

March 20-23, 2012.

Email: veronique.de.ulaemick@nlb.ac.be, www.intensive.care

$15^{\text {th }}$ World Congress of Anesthesiologists. Buenos Aires, Argentina.

March 25-30, 2012. www.wca2012.com

92 ${ }^{\text {nd }}$ Annual Meeting Association of Thoracic Surgeons. San Francisco, California.

April 28 - May 2, 2012. www.aats.org $15^{\text {th }}$ World Congress of Pain Clinicians. Granada, Spain. June 27-30, 2012. Email: WSPC2012@kenes.com

$13^{\text {th }}$ International Meeting of Cardiothoracic and Vascular Anesthesia and the New Zealand Anesthesia

Annual Scientific Meeting. Auckland, New Zealand.

November 14-17, 2012. www.iccva2012.com

$5^{\text {th }}$ International Congress: Aortic Surgery and Anesthesia «How to do it». Milano, Italy.

December 2012 (DTBA). www.aorticsurgery.it 